\section{A CASE OF \\ LARGE BLOOD CYST IN THE ARACHNOID SPACE SIMULATING BRAIN TUMOUR; OPERATION ; RECOVERY.}

BY JAMES TAYLOR, M.D. EDIN., F.R.C.P. LOND., PHYSICIAN FOR OUT-PATIENTS TO THE NATIONAL HOSPITAL FOR THE PARALYSED AND EPILEPTIC, QUEEN-SQUARE;

$$
\text { AND }
$$

CHARLES A. BALLANCE, M.S. Lond., F.R.O.S. ENG., SURGEON TO THE NATIONAT HOSPITAT FOR THE PARALYSKD AND EPILEPTIC, QUEEN-SQUARE.

THE patient was a man, 34 years of age, His family history is marked by a clear tendency to mental instability. His mother committed suicide, one sister is now in an asylum, and an aunt has been temporarily insane. His father died 20 years ago. A "fit" is said to have been the cause of death, but no more precise data are available. The patient had scarlet fever in childhood and a severe attack of enteric fever when 19 years old. He denied having had syphilis. He had been moderate in the use of alcohol and tobacco. In February, 1902, he accidentally fell on his way to his work, striking the right side of the head against a stone wall with some violence. The fall was so severe in its effect as to necessitate his return home and he was unable to work that day. The present illness began in May, 1902, some three months after the fall, with headache. This at first was entirely relieved by bromide and antipyrin, but returned after being relieved for three weeks. From that time it appears to have been uninfluenced by treatment. The headache was described as a shooting pain referred to the right side of the head with dull aching over the right eyelorow. No optic neuritis was detected at this time. On July 2 nd he went to Dover but ten days later was brought home, as he began to have difficulty in walking and was becoming dull mentally. Whes again examined he was drowsy and the simplest mental process seemed to require great effort. He was unable to walk without assistance and there was weakness of the left arm and leg variable in its degree. The pain in the head had in no way abated. Some blurring of the right optic disc was noticed about this time. He was admitted into a local hospital where he remained a month. While there he was noisy and troublesome at night and lost control over the sphincters. He was considered to be insane. There was now increase of the left knee-jerk and ankle clonus was present on the left side. Early in August he was seen by one of us (J. T.) at the instance of Dr. L. Cooper of Rochester, to whom we are indebted for the history of the case. The presence of intense optic neuritis favoured the diagnosis of tumour of the brain and the variable character of the paralysis of the left arm suggested that it was a fluid tumour, possibly an abscess. The patient was therefore admitted to the National Hospital for the Paralysed and Epileptic on August 20 th, 1902. We are much indebted to the careful notes of the house physician, Dr. Gordon Holmes, for the following particulars and we desire to express our appreciation of Dr. Holmes's zeal and skill in the management of the case.

On admission the general health was not much deteriorated. Some loss of memory for recent events was present. The gait was irregular and swaying. The deep reflexes were exaggerated on the left side. The loss of sphincteric control and the left-sided paralysis were no longer present. Optic neuritis (swelling 4 D.) with retinal hæmorrhages existed on the right side. There was less marked optic neuritis (swelling $1.5 \mathrm{D}$.) without hæmorrhages on the left side. Horizontal nystagmus was specially marked in the right eye and on movement of the eyes to the right. The headache was intermittent. There was doubtful tenderness over the right frontal region on percussion. The patient had been taking iodide of potassium prior to admission and this drug was continued in larger doses but it produced no appreciable effect. A diagnosis of cerebral tumour, probably in the right frontal region, was made and operation was decided upon.

First stage of the operation. -On Sept. 1st, chloroform having been given, a flap including most of the anterior half of the right side of the scalp was thrown down and the underlying bone over a large area was removed with the saw by the "chess-board" method. The dura mater was very tense. The scalp flap was then sutured into position.

Second stage of the operation-On Sept. 6th chloroform was again given and the scalp flap was thrown down. The dura mater was yet more tense and prominent. On incision of the dura mater a tense, fluctuating and pulsating swelling of a maroon-red colour was exposed. It completely filled the floor of the wound and bulged through the opening in the skull. The pulsation was expansile like that of an aneurysm. The opening in the skull was insufficient to expose the edges of the cyst. The cerebral hemisphere was displaced inwards and so compressed laterally as to present the appearance of a ridge about one inch in width on the median aspect of the tumour. The opening in the skull was further enlarged and this stage of the operation was concluded by resuturing the flap.

Third stage of the operation.-On Sept. 18th a temporary ligature was first placed on the internal carotid artery a short distance above its origin. The wound in the head was then reopened; the opening in the bone measured five and a half inches antero-posteriorly by four and a half inches vertically. The tumour, which was not adherent to the brain, was cautiously inveigled from its bed in the arachnoid space by manipulation with the fingers. Its anterior, posterior, and inferior margins were lifted without great difficulty from within the skull, leaving a large space between the brain and the bone. It was attached by a slight adhesion to the dura mater near the posterior inferior angle of the parietal bone and to the cerebral arachnoid over the inferior aspect of the temporo-sphenoidal lobe. It had no connexion with any named vessel, but each of these adhesions was vascular. There were also certain delicate threads of connective tissue between the wall of the cyst and the wall of the cavity in which it lay. In front it almost reached the anterior extremity of the frontal lobe; above it extended to within one inch of the superior longitudinal sinus : below it compressed the apex of the temporo-sphenoidal lobe, extending under the brain to the clinoid processes while behind it was spread over the surface of the parietal and occipital lobes. On removal it measured seven inches long, four and a half inches from above downwards, and one and a half inches in thickness. When within the skull the tumour probably occupied a larger superficial area and was less in width as a consequence of the great pressure to which it was subjected. Its removal was only attended with slight bleeding. The hemisphere of the brain was much compressed and its convolutions were flattened. It visibly expanded when the ligature was removed from the internal carotid. The scalp flap was replaced and sutured in the usual way.

The patient made a good recovery and was discharged well on Jan. 15th, 1903. He had a fit in February. He was in perfect health on May 26 th last and was present at the clinical lecture at the hospital on that day.

This case naturally raises the old question of the occurrence of hremorrhages and false membranes within the arachnoid space so ably dealt with by Dr. J. Wiglesworth in the Journal of Mental Bcience for January, 1888. In 400 post mortem examinations of insane patients he found blood or membrane, or both combined, in the cerebral subdural space in 42 instances, of which 22 were cases of general paralysis of the insane. Certainly in some of these cases there was a history of traumatism, such as falling off a chair. Thus of one case it was said, "She fell off her chair one morning in a fit; two hours after this she presented all the symptoms of a copious hæmorrhage." At the death of this patient nine months afterwares a thick laminated membrane was, as might well have been expected, found in the subdural space. It is worthy of note that our patient had a fall with traumatism of the head three months before his urgent symptoms came on. In a few cases it is clear from the history that the hremorrhage occurred independently of traumatism ; but it is not always possible to determine in cases where there is a history of a fall whether the fall was the cause of the hæmorrhage or the hromorrhage the cause of the fall. It is well known that blows on the bead do produce serious hremor rhages within the skull and yet the symptoms are delayed for hours or days. Whether, however, the hæmorrhage is due to traumatism or not hæmatoma will in any case result.

It was shown many years ago by the late $\mathrm{Mr}$. Morrant Baker, ${ }^{1}$ that a hæmatoma may slowly increase in size by constant slight fresh hæmorrhages into it, a condition which 
is well known in surgery in the history of an ordinary bæmatocele. Hæmatoma in the arachnoid cavity therefore may, and probably in some cases does, behave exactly as does a hæmaioma in the tunica vaginalis testis.

'I'here has heen much discussion by various authorities as to the na'ure and cause of the fibrous cyst walls which are formed, hnt it does not appear to us that they present much difficult $\mathrm{A}$ growing hæmatoma contains, besides fresh blood, hlood-clot; the latter, being a dead tissue, coustitutes a foreign body, and like a bullet or any other foreign body, it becomes surrounded by a fibrous areolar capsule. The reason why these arachnoid hæmatomata are so relatively common in general paralytios is apparently because their vessels suffer from a syphilitic process.

It had been proposed to send our patient to a lunatic asylum and it is curious to conjecture what would have happened had this fate overtaken him. He might well have passed muster, at least at first, as a general paralytic, but it is hardly likely that he would have been duly numbered and labeled as such.

FIG. 1.

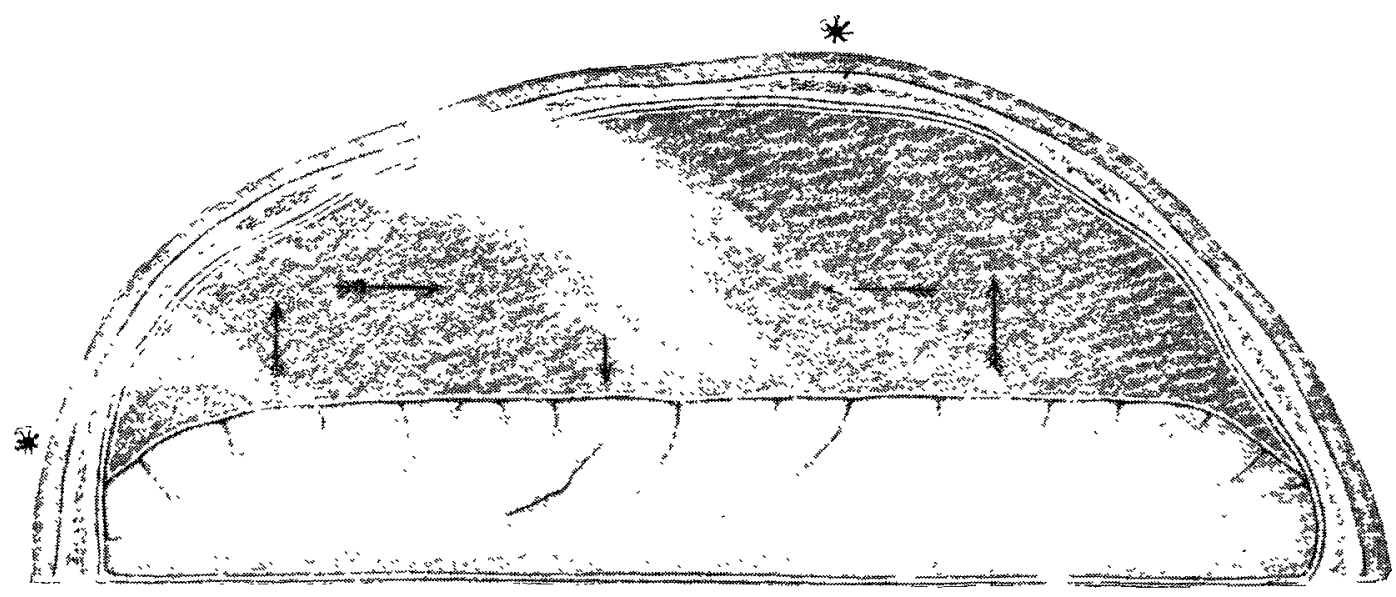

Diagram of a horizontal section of the head to show the position of the "cyst," the compression of the cerebral hemisphere, and the occurrence of expansile pulsation in the tumour. Half natural size. The size of the drawing corresponds to the cast of the patient's head which was mare when he was convalescent. The marks * show the extent of the opening in the skull. The tumour being fluid the pulsations of the brain were transmitted in every direction ; hence when the finger and thumb grasped the centre of the tumour (see arrows in the centre of the cyst) they were separated by an expansile pulsation comparable to that which obtains in aneurysm.

FIG. 2.

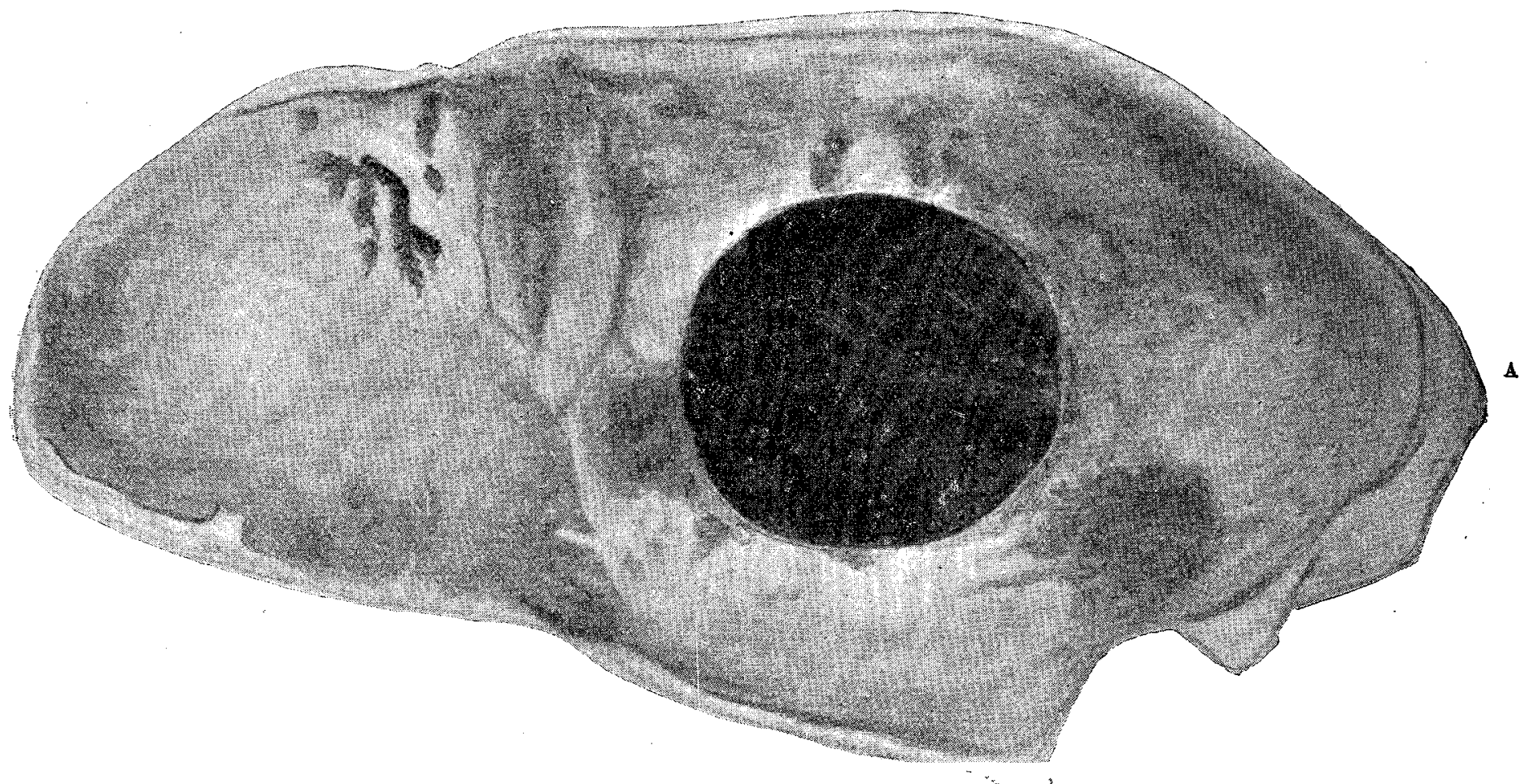

Reproduction of a photograph of a coloured drawing of the outer surface of the tumour (hæmatoma of the arachnoid cavity) which is in the Museum of the Royal College of Surgeons of England (3837 A). $\frac{6}{t h s}$ natural size (M. H. Lapidge). A, Anterior border of the eyst. The following description of the tumour is by Mr. S. G. Shattock. A somewhat flattened, irregularly oval cyst, about six inches in length and over three inches in extreme breadth, which was removed by operation from the subdural space. The external surface is almost everywhere smooth, but here and there is slightly roughened at spots where it has been detached through slender adhesions. The opposite aspect which lay against the cerebral hemisphere is less smooth and for the most part is covered with a thin layer of lymph or decolourised blood-clot, in which the impress of the subjacent cerebral vessels is particularly obvious. No separable membrane can be demonstrated on either a obvisu the

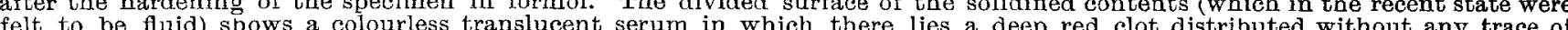
felt to

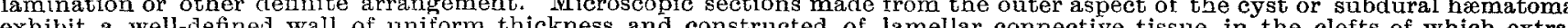
exhibit surface this is sharply demarcated and is not undergoing organised incorporation with the wall of the cyst. 
At the second stage of the operation when the cyst was exposed the expansile pulsation (the nature of which was not at the moment obvious but which is explained by the accompanying illustration-Fig. 1) suggested the possibility of an aneurysm. It was therefore decided to enlarge the opening in the bone and to remove the tumour on a subsequent occasion.

Such large blood cysts in the arachnoid space must be rare. The museums which we have inspected contain no such large cyst, but one is figured by Hamilton. ${ }^{2}$ There can be no doubt that the condition is not due to inflammation but is a simple hæmorrhage.

\section{A CASE OF ECTOPIA CORDIS.}

By SiR ISAMBARD OWEN, M.A., M.D. CANTAB., F.R.C.P. LOND.,

PHYSICLAN TO, AND LECTURER ON THE PRINCIPLES AND PRACTICE OF PHYSIC AT, ST. GEORGE'S HOSPITAL

$$
\text { AND }
$$

MORRIS J. WILLIAMS, L.S.A.

THE patient was a girl, aged 14 years. She had suffered from an attack of rheumatic fever in 1901 but was not then attended by a medical man. In 1903 she came under $\mathrm{Mr}$. Williams's care in a fresh attack of rheumatic fever, followed by anasarca, the urine having been albuminous throughout. She was seen by Sir Isambard Owen at St. George's Hospital in consultation with Mr. Williams on May 22nd. The following physical signs were then present in the thorax. The area of cardiac dulness was as indicated by the shading in Fig. 1 which is copied from a diagram made at the time.

\section{FIG. 1.}

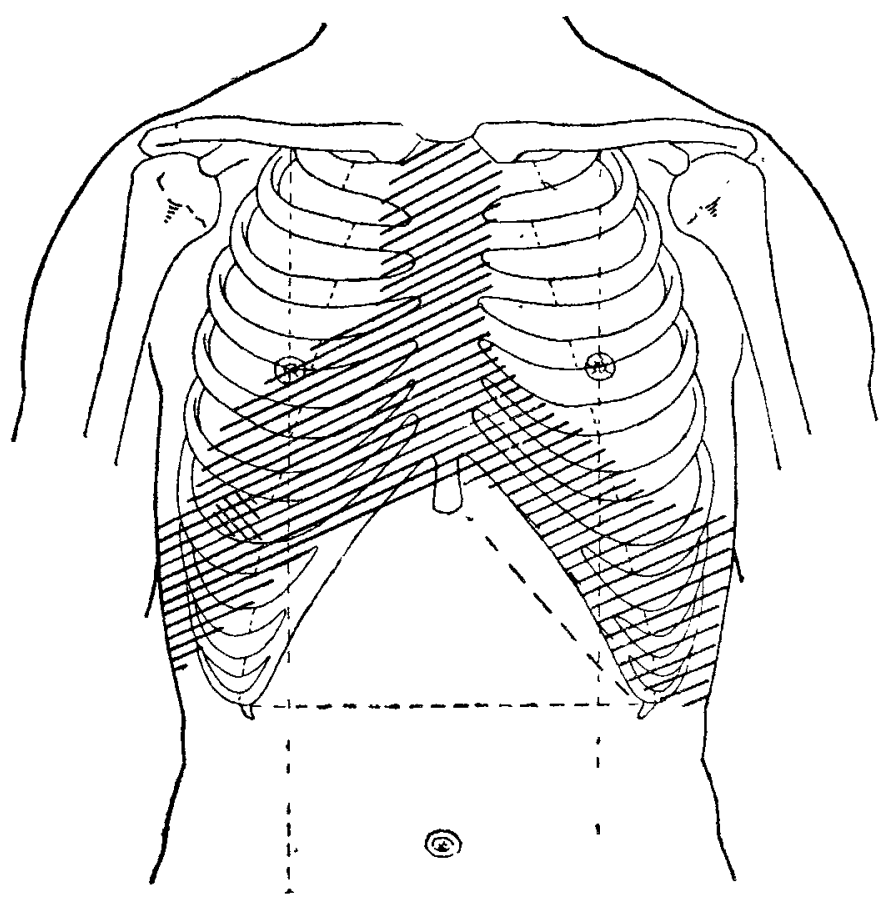

The apex beat of the heart was, as shown on the figure by cross-hatching, in the sixth right interspace, nearly an inch to the right of the nipple line. No impulse was felt elsewhere. A systolic murmur was heard over all the dull area, culminating at the apex beat; it was well conducted into the right axilla and was well heard at the angle of the right scapula but not at all at that of the left. A shorter and rougher double murmur culminated in the second right space close to the sternum (the normal "aortic area"); it was conducted down the sternum and was well heard at the lower part of its left margin, but it was not heard in the neck. The murmurs were but faintly heard over the normal præcordial area to the left of the sternum, except at its sternal margin. No murmur was heard in the abdomen. The pulse presented no special feature. As shown in the illustration, what was presumed to be liver dulness was found on

2 Text-book of Pathology, vol. ii., part 2, p. 604. the left side and what appeared to be splenic dulness was found on the right side. The edge of the liver was doubtfully felt in the left hypochondrium in the position of the broken line in the illustration. The bases of the lungs were not very resonant but there was no abnormality of the breath sounds or any other indication of past or present disease of the lung or the pleura. There was a little ascites present but not enough to interfere with the action of the diaphragm. Nothing else remarkable was noticed in the patient and the malposition of the heart was verified by an X-ray examination. A skiagram was taken by Mr. Frank Addyman, superintendent of the $x$-ray department of the hospital ; it represented the thorax viewed from the back. The position of the heart, mainly to the right of the middle line, and the pointing of the apex to the right were clearly shown. The transparency of the heart to the rays, Mr. Addyman found, was unusually great, whilst that of the lungs was less than usual.

The patient was seen again by Sir Isambard Owen on June 22nd in consultation with Mr. Williams. The areas of dulness and the position of the apical impulse on this occasion were as indicated by the shading in Fig. 2

FIG. 2.

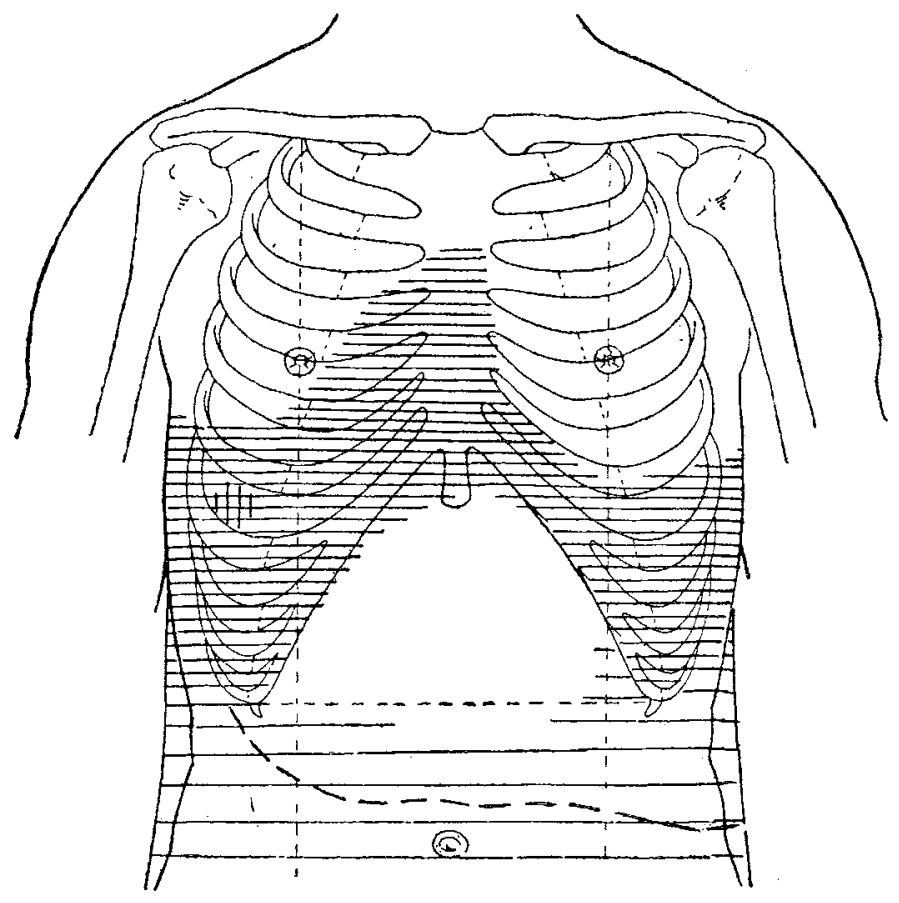

similarly copied from a diagram taken at the time. The liver was now greatly enlarged, its edge being plainly palpable in the position of the broken line in the figure. The cardiac impulse was felt over the entire area of cardiac dulness, the sternal portion excepted, and not at all to the left of the sternum. 'The localisation and extension of the murmurs were as on the previous occasion, with the exception that the basic point of culmination was in the third right space instead of in the second. The bases of the lungs were dull and the breath and voice sounds were deficient over the dull area. Ascites was still present.

The special interest of the case, as a living example of a rather rare condition, was due to the presence of valve lesions. The consequent enlargement of the heart enabled its abnormal position and direction to be the more obviously traced, while the localisation and conduction of the murmurs afforded a clue to the situation and direction of the orifices, at least of the aortic side. There appeared to be almost, if not quite, complete dexiocardia, but the course of the aorta was left in doubt, as the basic murmurs, which were very unlikely to be of pulmonary origin, culminated to the right and not to the left of the sternum. The results of palpation and percussion appeared to indicate a reversal of the position of the liver and the spleen. The $x$ rays failed to show the localisation of these organs either on the screen or on the skiagram. As far as can be made out the health and comfort of the patient were in no way affected by the malposition. The valve lesions, it may with probability be assumed, originated in rheumatic endocarditis in 1901 or in the present year. 